\title{
Jaringan Syaraf Tiruan untuk Memprediksi Penjualan Kelapa Sawit Menggunakan Algoritma Backpropagation
}

\author{
Delima Sinaga ${ }^{1}$, Solikhun ${ }^{2}$, Iin Parlina ${ }^{3}$ \\ STIKOM Tunas Bangsa Pematangsiantar \\ delimasinaga231@gmail.com, solikhun@amiktunasbangsa.ac.id,iin@amiktunasbangsa.ac.id
}

\begin{abstract}
This study discusses the prediction of palm oil sales using artificial neural networks, which is one of the artificial representations of the human brain that always tries to simulate the learning process of the human brain. The application uses a backpropagation algorithm where the data entered is the number of sold. Then artificial neural networks are formed by determining the number of units per layer. After the networks is formed, training is carried out from the grouped data. Experiments are carried out with an architecture consisting of input units, hidden units, output units and architecture. Testing is done with matlab software. For now the competition for palm oil sales is getting tougher. Predictions with the best accuracy use the 12-2-1 architecture with an accuracy rate of $92 \%$ and the lowest level of accuracy using 12-6-1 architecture with an accuracy rate of 58\%.
\end{abstract}

Keyword : prediction, artificial neural networks, sales.

Abstrak - Penelitian ini membahas tentang prediksi penjualan kelapa sawit menggunakan Jaringan Syaraf Tiruan yang merupakan salah satu representasi buatan dari otak manusia yang selalu mencoba untuk mensimulasikan proses pembelajaran otak manusia. Penerapannya menggunakan algoritma Backpropagation dimana data yang diinputkan adalah Jumlah Terjual. Kemudian dibentuk Jaringan Syaraf Tiruan dengan menentukan jumlah unit setiap lapisan. Setelah jaringan terbentuk, dilakukan training dari data yang telah dikelompokkan tersebut. Percobaan dilakkukan dengan arsitektur jaringan yang terdiri dari unit masukan, unit tersembunyi, unit keluarannya dan aristektur. Pengujian dilakukan dengan perangkat lunak Matlab. Untuk saat ini persaingan penjualan kelapa sawit semakin ketat. Prediksi dengan tingkat akurasi terbaik menggunakan arsitektur 12-21 dengan tingkat akurasi sebesar 92\% dan tingkat akurasi terendah menggunakan arsitektur 12-6-1 dengan tingkat akurasi sebesar 58\%.

Kata Kunci : prediksi,Jaringan Syaraf Tiruan, Penjualan, backpropagation

\section{PENDAHULUAN}

Dunia usaha yang terus berubah dengan cepat, serta banyaknya persaingan pengusaha yang semakin banyak, mengharuskan perusahaan untuk mampu memprediksi berbagai kemungkinan yang terjadi di masa depan. Kegiatan prediksi atau forecast masa depan merupakan salah satu usaha perusahaan sebagai dasar pengambilan keputusan strategis dalam kelangsungan usaha khususnya UD. Doge Doge. Prediksi dilakukan bertujuan ubtuk mengetahui perkiraan penjualan yang akan datang apakah sudah memenuhi target penjualan atau belum. Dengan adanya prediksi maka perusahaan akan dapat melakukan pengambilan keputusan yang tepat. Jarringan Syaraf Tiruan dengan Algoritma Backpropagation merupakan sebuah metode prediksi untuk penjualan kelapa sawit. Konsepnya dengan cara 
memasukkan data dari periode sebelumnya kedalam sistem kemudian dilakukan proses pelatihan menggunakan Jaringan Syaraf Tiruan dengan Algoritma Backpropagation.

\section{METODOLOGI PENELITIAN}

Kecerdasan Buatan (Artificial Intelligence) merupakan salah satu bagian dari ilmu komputer yang mempelajari bagaimana membuat mesin (komputer) dapat melakukan pekerjaan seperti dan sebaik yang dilakukan oleh manusia bahkan bisa lebih baik daripada yang dilakukan manusia [1]-[3]. Jaringan Syaraf Tiruan merupakan salah satu representasi buatan dari otak manusia yang selalu mencoba untuk mensimulasikan proses pembelajaran otak manusia tersebut. Backpropagation merupakan suatu teknik pembelajaran atau pelatihan jenis supervised learning yang sering digunakan. Metode ini merupakan salah satu metode yang sangat baik dalam menangani masalah pengenalan pola yang kompleks. Prediksi merupakan penelaahan tentang situasi yang menyelimuti lingkungan masa datang sebagai dasar pengambilan keputusan [4]-[10].

\subsection{Metode Pengumpulan Data}

a. Observasi, penulis dalam mengumpulkan data dengan mengamati atau meninjau secara cermat dan langsung di lokasi penelitian untuk mengetahui kondisi yang terjadi, serta memilah data mana yang tepat digunakan sebagai sumber data untuk penelitian.

b. Wawancara, penulis melakukan tanya jawab terlebih dahulu kepada pihak yang bersangkutan tentang bagaimana data tentang penjualan dapat diperoleh dan apakah data tersebut bisa untuk digunakan peneliti sebagai bahan untuk penelitian.

c. Studi Literatur, penulis mempelajari cara dan pola pengumpulan data sebaikbaiknya dengan pedoman-pedoman yang terdapat pada buku-buku, materi ajar dan penelitian terdahulu dari bagian perpustakaan agar tidak salah dalam pengumpulan data yang akan digunakan.

d. Penentuan Pola, Tahap ini yakni melakukan pemilihan arsitektur agar selanjutnya dapat dilakukan pelatihan dan pengujian data.

e. Pelatihan Data, sudah ditransformasi dan pola sudah ditentukan selanjutnya dilakukan pelatihan data menggunakan software Matlab.

Tabel 1. Data Penjualan Kelapa Sawit

\begin{tabular}{|l|c|c|c|c|}
\hline \multicolumn{5}{|c|}{ Data Penjualan (Ton) UD. Doge Doge, Bandar Pasir Mandoge } \\
\hline Bulan / Tahun & 2015 (Ton) & 2016 (Ton) & 2017 (Ton) & 2018 (Ton) \\
\hline Januari & 1140 & 1680 & 1470 & 1140 \\
\hline Februari & 1835 & 1485 & 1625 & 1368 \\
\hline Maret & 1180 & 1260 & 1594 & 1420 \\
\hline April & 1765 & 1337 & 1345 & 1629 \\
\hline Mei & 1690 & 1540 & 1752 & 1850 \\
\hline Juni & 1360 & 1867 & 1846 & 1670 \\
\hline Juli & 1089 & 1625 & 1780 & 1543 \\
\hline Agustus & 1467 & 1196 & 1598 & 1560 \\
\hline September & 1635 & 1028 & 1672 & 1770 \\
\hline
\end{tabular}




\begin{tabular}{|l|c|c|c|c|}
\hline \multicolumn{5}{|c|}{ Data Penjualan (Ton) UD. Doge Doge, Bandar Pasir Mandoge } \\
\hline Bulan / Tahun & 2015 (Ton) & 2016 (Ton) & 2017 (Ton) & 2018 (Ton) \\
\hline Oktober & 1550 & 1810 & 1910 & 1490 \\
\hline November & 1390 & 1415 & 1760 & 1658 \\
\hline Desember & 1287 & 1726 & 1529 & 1867 \\
\hline
\end{tabular}

Pada tabel 1 diatas merupakan data penjualan kelapa sawit tahun 2015 sampai dengan tahun 2018 pada UD. DOGE DOGE, Bandar Pasir Mandoge yang digunakan pada penelitian ini.

\subsection{Tahapan Penelitian}

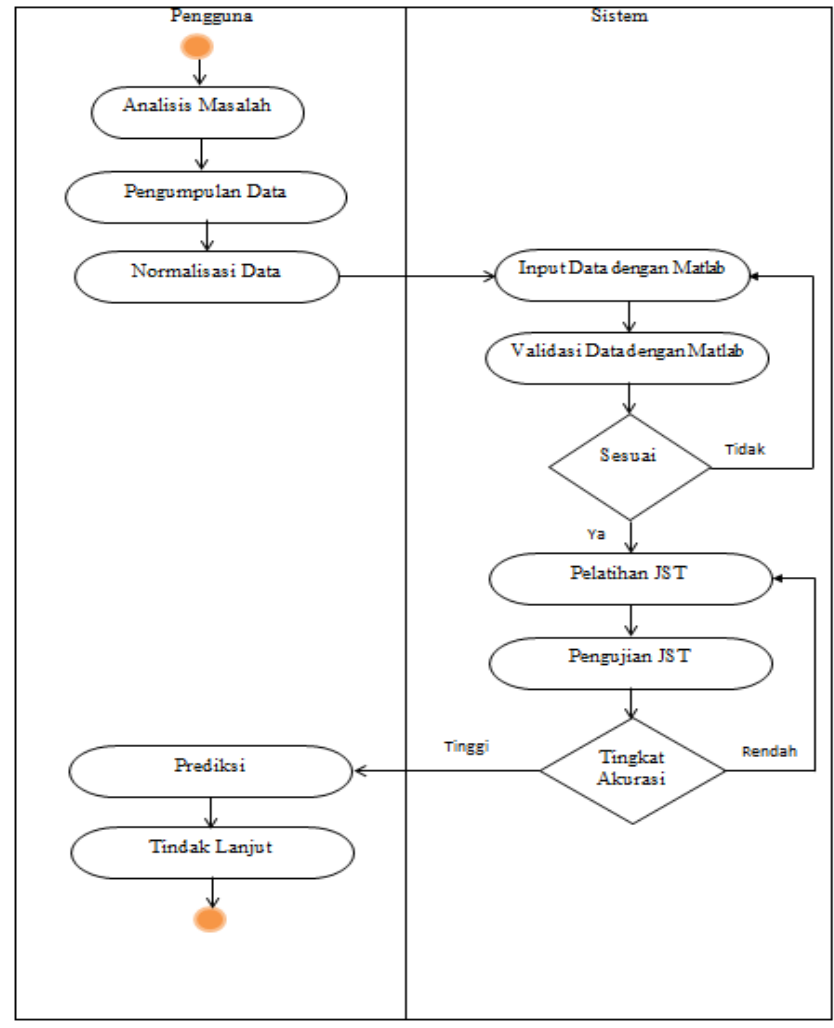

Gambar 1. Activity Diagram

Pada gambar diatas merupakan alur aktivitas yang dilakukan dalam penelitian pada sistem yang digunakan. Penulis mengidentifikasi masalah dan tujuan penelitian yang dilakukan, mengumpulkan data menggunakan data kuantitatif yang diberikan oleh pihak UD. DOGE DOGE, kemudian memvalidasikan data dengan menggunakan aplikasi Matlab untuk mengukur target error. Hasil dari informasi yang diberikan aplikasi Matlab maka penulis memuat pola Jaringan Syaraf Tiruan dan analisa yang telah dilakukan perhitungan sistem Jaringan Syaraf Tiruan proses data dan pelatihan kemudian proses data pengujian menggunakan algoritma Backpropagation dengan menginisialisasi, mengaktivasi dan menghitung bobot pelatihan dengan error terkecil dan kemudian proses normalisasi. 


\section{HASIL DAN PEMBAHASAN}

Hasil dari penelitian dan implementasi yang dilakukan adalah seagai berikut : Normalisasi bertujuan untuk mempermudah dalam melakukan pengolahan data menggunakan software Matlab. Normalisasi menggunakan formula berikut [11][24]:

$$
x^{\prime}=\frac{0,8(x-a)}{(b-a)}+0,1
$$

Keterangan:

x' : Data Transformasi

$\mathrm{x} \quad$ : Data yang akan ditransformasi

a : Data minimum rata-rata

b : Data Maximum rata-rata

Melakukan normalisasi akan membagi data menjadi 2 (dua) yakni, data pelatihan (training)dan data pengujian (testing). Data yang ada di atas dilakukan proses normalisasi agar dapat di baca oleh sistem yang di gunakan yaitu matlab $R 2011 b$.

\subsection{Pelatihan Dan Pengujian Data dengan Arsitektur 12-2-1}

Layer masukan menggunakan 12 Neuron, layer tersembunyi 2 neuron serta 1 neuron keluaran.Source code pelatihan backpropagationyang digunakan dengan aplikasi Matlab $R 2011 b$ sebagai berikut:

>> net=newff(minmax (P),[7,1],\{'tansig','logsig'\},'traingd');

Perintahini digunakan untuk membentuk jaringan pada backpropagation yang mempunyai 7 neuron hidden dan 1 neuron target.

>> net.IW $\{1,1\}$;

Net.IW $\{1,1\}$ bobot pertama yang digunakan untuk bobot hidden.

$>$ net.b $\{1\}$;

Net.b $\{1\}$ bias yang digunakan untuk bias hidden.

$>$ net.LW $\{2,1\}$;

Net.LW $\{2,1\}$ bobot kedua yang digunakan untuk bobot keluaran.

$>$ net.b $\{2\}$;

bias yang digunakan untuk bias keluaran.

> net.trainParam.epochs $=100000$;

Perintah untuk menentukan jumlah iterasi (epochs) maksimum pelatihan.

$>$ net.trainParam.goal =0.001;

Perintah untuk menentukan batas MSE agar iterasi dihentikan.

$>$ net.trainParam. $L r=0.01$;

Perintah yang digunakan untuk menentukan laju pembelajaran (Learning Rate).

$>$ net.trainParam.show = 1000;

Perintah yang digunakan untuk menampilkan frekuensi perubahan MSE.

> net=train(net, $P, T)$

Perintah ini akan memunculkan jaringan hasil pelatihan.

$>[a, P f, A f, e, P e r f]=\operatorname{sim}($ net $, P,[],[], T)$

Perintah ini digunakan untuk melihat hasil yang dikeluarkan oleh jaringan. 
Pelatihan dan pengujian Jaringan Syaraf Tiruan dengan arsitektur 12-2-1 dapat dilihat pada gambar 2 .

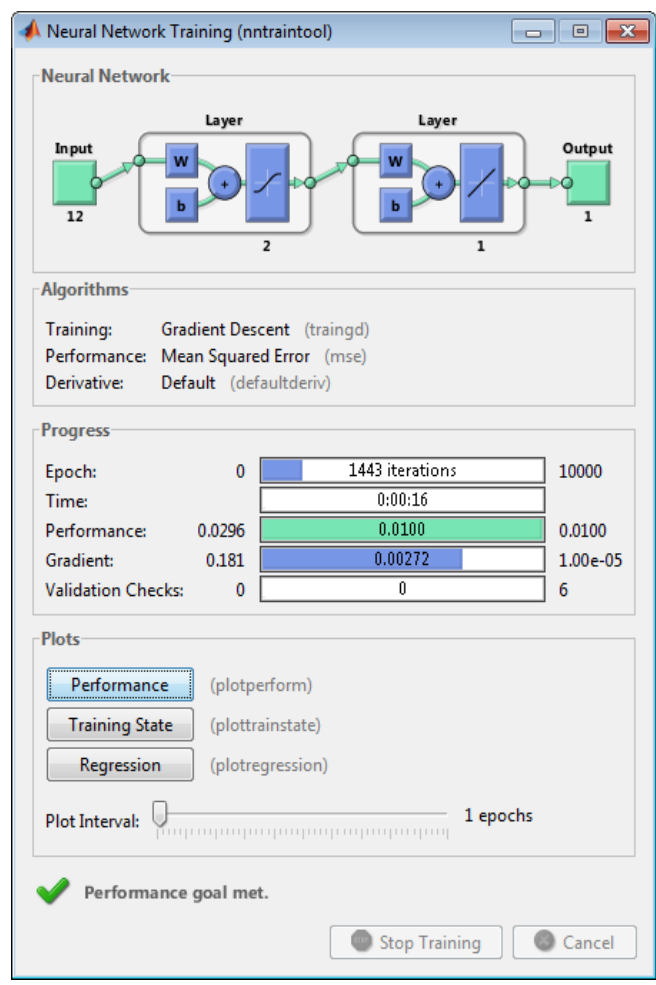

Gambar 2. Pelatihan Menggunakan Arsitektur 12-2-1

Pada gambar 2 terdapat model jaringan dengan arsitektur 12-2-1 menghasilkan epoch sebesar 1443, dengan waktu 00:16 detik.

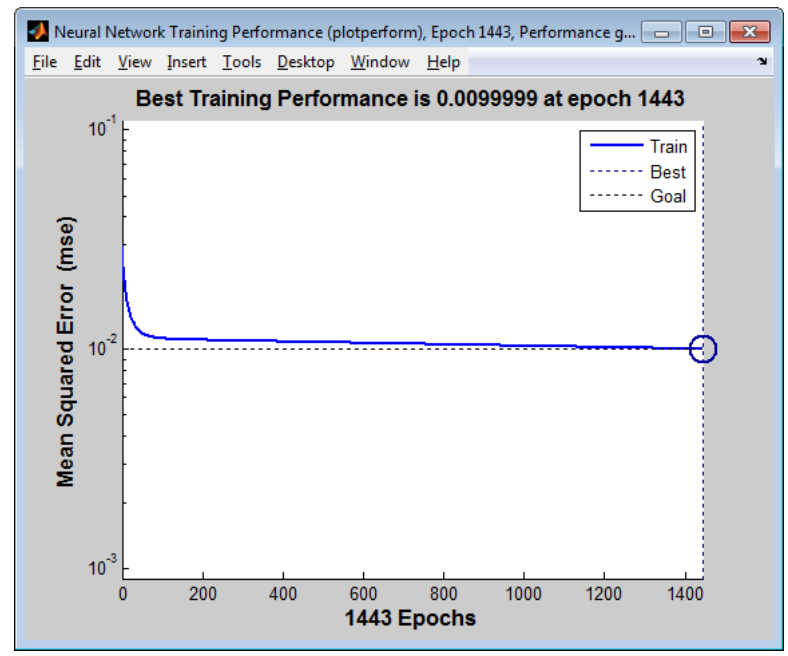

Gambar 3. Performance Pelatihan Menggunakan Arsitektur 12-2-1

Pada Gambar 3 menunjukkan error goal (MSE) pada pelatihan ini sebesar 0,0099999 dicapai pada epoch yang ke 1443. Berikut akurasi data pelatihan arsitektur 12-2-1, dapat dilihat pada tabel 2:

Prediksi Penjualan Kelapa Sawit Menggunakan Algoritma Backpropagation (Delima Sinaga)| 422 
Tabel 2. Akurasi Data Pelatihan Arsitektur 12-2-1

\begin{tabular}{|c|c|c|c|c|}
\hline Pola & Target & Output & Error & SSE \\
\hline Pola1 & 0,5009 & 0,7053 & $-0,2044$ & 0,0418 \\
\hline Pola2 & 0,6415 & 0,6825 & $-0,0410$ & 0,0017 \\
\hline Pola3 & 0,6134 & 0,6243 & $-0,0109$ & 0,0001 \\
\hline Pola4 & 0,3875 & 0,3831 & 0,0044 & 0,0000 \\
\hline Pola5 & 0,7567 & 0,6406 & 0,1161 & 0,0135 \\
\hline Pola6 & 0,8420 & 0,8047 & 0,0373 & 0,0014 \\
\hline Pola7 & 0,7821 & 0,6757 & 0,1064 & 0,0113 \\
\hline Pola8 & 0,6170 & 0,6290 & $-0,0120$ & 0,0001 \\
\hline Pola9 & 0,6841 & 0,6867 & $-0,0026$ & 0,0000 \\
\hline Pola10 & 0,9000 & 0,7467 & 0,1533 & 0,0235 \\
\hline Pola11 & 0,7639 & 0,7466 & 0,0173 & 0,0003 \\
\hline Pola12 & 0,5544 & 0,7164 & $-0,1620$ & 0,0262 \\
\hline & & & Jumlah SSE & 0,11996814 \\
\hline & & & MSE & 0,00999734 \\
\hline
\end{tabular}

Pada tabel 2 terdapat pola $1 \mathrm{~s} / \mathrm{d} 12$ adalah pola yang dipakai dalam data pelatihan. Nilai Target diperoleh dari tabel data pelatihan yang sudah dinornalisasi. Nilai Output diperoleh dari rumus $[a, P f, A f, e, P \operatorname{erf}]=\operatorname{sim}($ net, $P,[],[], T)$ yang dimasukkan pada aplikasi Matlab dari input dan data target data pelatihan. Nilai Errordiperoleh dari : Target-Output. SSE diperoleh dari : Error^2(^: Pangkat). Jumlah SSE adalah total dari keseluruhan SSE. MSE diperoleh dari : jumlah SSE / 12 (jumlah data). Hasil bernilai Benar apabila nilai SSE $<=0,1$ adalah target error dari pelatihan backpropagation. Berikut akurasi data pengujian arsitektur 12-2-1, dapat dilihat pada tabel 3 :

Tabel 3. Akurasi Data Pengujian Arsitektur 12-2-1

\begin{tabular}{|c|c|c|c|c|c|c|}
\hline Bulan & Pola & Target & Output & Error & SSE & Hasil \\
\hline $\mathbf{1}$ & Pola13 & 0,1524 & 0,6814 & $-0,5290$ & 0,2798 & 0 \\
\hline $\mathbf{2}$ & Pola 14 & 0,3869 & 0,2187 & 0,1682 & 0,0283 & 1 \\
\hline $\mathbf{3}$ & Pola 15 & 0,4404 & 0,4690 & $-0,0286$ & 0,0008 & 1 \\
\hline $\mathbf{4}$ & Pola 16 & 0,6553 & 0,6565 & $-0,0012$ & 0,0000 & 1 \\
\hline $\mathbf{5}$ & Pola 17 & 0,8825 & 0,6850 & 0,1975 & 0,0390 & 1 \\
\hline $\mathbf{6}$ & Pola 18 & 0,6974 & 0,6153 & 0,0821 & 0,0067 & 1 \\
\hline $\mathbf{7}$ & Pola 19 & 0,5668 & 0,3818 & 0,1850 & 0,0342 & 1 \\
\hline $\mathbf{8}$ & Pola 20 & 0,5843 & 0,6679 & $-0,0836$ & 0,0070 & 1 \\
\hline $\mathbf{9}$ & Pola 21 & 0,8003 & 0,6815 & 0,1188 & 0,0141 & 1 \\
\hline $\mathbf{1 0}$ & Pola 22 & 0,5123 & 0,7315 & $-0,2192$ & 0,0480 & 1 \\
\hline $\mathbf{1 1}$ & Pola 23 & 0,6851 & 0,6036 & 0,0815 & 0,0066 & 1 \\
\hline $\mathbf{1 2}$ & Pola 24 & 0,9000 & 0,7176 & 0,1824 & 0,0333 & 1 \\
\hline & & & & Jumlah SSE & 0,49793487 & $\mathbf{9 2 \%}$ \\
\hline
\end{tabular}

Dari arsitektur 12-2-1 pada tabel 3 dapat diketahui bahwa tingkat akurasi Pengujian sebesar $92 \%$. 
Pola 13 s/d 24 adalah pola yang dipakai dalam data pengujian.Nilai Target diperoleh dari tabel data pengujian yang sudah dinormalisasi. Nilai Output diperoleh dari rumus $[a, P f, A f, e, P e r f]=\operatorname{sim}($ net, $P,[],[], T)$ yang dimasukkan pada aplikasi Matlab dari input dan target data pengujian. Nilai Errordiperoleh dari : Target-Output. SSE diperoleh dari : Error^2. Jumlah SSE adalah total dari keseluruhan SSE. MSE diperoleh dari : Jumlah SSE / 12 (jumlah data). Hasil bernilai 1 (satu atau benar) apabila nilai SSE $<=0,1$ dan hasil bernilai 0 (nol atau salah) apabila nilai SSE $>0,1$ adalah target error dari pengujian backpropagation. Akurasi (\%) diperoleh dari : Jumlah Benar / $12 * 100$.

\subsection{Perbandingan Akurasi Pola jaringan}

Tabel 4. Kesimpulan Pelatihan dan Pengujian Jaringan

\begin{tabular}{|c|c|c|c|c|c|c|}
\hline \multirow{2}{*}{ No } & Arsitektur & \multicolumn{3}{|c|}{ Training } & \multicolumn{2}{c|}{ Testing } \\
\cline { 3 - 7 } & & Epoch & Waktu & MSE & MSE & Akurasi \\
\hline $\mathbf{1}$ & $12-2-1$ & 1443 & $00: 16$ & 0,00999734 & 0,04149457 & $\mathbf{9 2 \%}$ \\
\hline $\mathbf{2}$ & $12-4-1$ & 751 & $00: 09$ & 0,00999268 & 0,06993323 & $\mathbf{8 3 \%}$ \\
\hline $\mathbf{3}$ & $12-6-1$ & 1244 & $00: 14$ & 0,01000121 & 0,07737224 & $\mathbf{5 8 \%}$ \\
\hline $\mathbf{4}$ & $12-7-1$ & 139 & $00: 02$ & 0,00998635 & 0,31604867 & $\mathbf{7 5 \%}$ \\
\hline $\mathbf{5}$ & $12-9-1$ & 120 & $00: 02$ & 0,00995036 & 0,28185618 & $\mathbf{5 8 \%}$ \\
\hline
\end{tabular}

Dari 5 pola di atas, Akurasi terbaik yang di peroleh adalah sebesar 92\% dan akurasi terendah adalah 58\%. Setelah arsitektur terbaik didapatkan, selanjutnya dilakukan prediksi untuk tahun kedepannya. Berikut tahapan-tahapan dalam melakukan prediksi menggunakan arsitektur 12-2-1.

Tabel 5. Prediksi Data Tahun 2019

\begin{tabular}{|c|c|c|c|c|}
\hline Bulan & Data Real & Target & Target Prediksi & Prediksi \\
\hline $\mathbf{1}$ & 1140 & 0,1524 & 0,17340 & 1160 \\
\hline $\mathbf{2}$ & 1368 & 0,3869 & 0,37120 & 1353 \\
\hline $\mathbf{3}$ & 1420 & 0,4404 & 0,40390 & 1385 \\
\hline $\mathbf{4}$ & 1629 & 0,6553 & 0,71550 & 1688 \\
\hline $\mathbf{5}$ & 1850 & 0,8825 & 0,73210 & 1704 \\
\hline $\mathbf{6}$ & 1670 & 0,6974 & 0,70780 & 1680 \\
\hline $\mathbf{7}$ & 1543 & 0,5668 & 0,57210 & 1548 \\
\hline $\mathbf{8}$ & 1560 & 0,5843 & 0,70410 & 1676 \\
\hline $\mathbf{9}$ & 1770 & 0,8003 & 0,71150 & 1684 \\
\hline $\mathbf{1 0}$ & 1490 & 0,5123 & 0,72370 & 1696 \\
\hline $\mathbf{1 1}$ & 1658 & 0,6851 & 0,70530 & 1678 \\
\hline $\mathbf{1 2}$ & 1867 & 0,9000 & 0,74420 & 1715 \\
\hline
\end{tabular}

Tabel 5 merupakan tahapan-tahapan melakukan prediksi, Berikut penjelasannnya.

Data real adalah data yang diperoleh dari data tahun terakhir. Data target diperoleh dari data Testing yang sudah di normalisasi. Target estimasi pada tabel diperoleh dari hasil pengujian menggunakan software Matlab R2011b, Adapun rumus yang digunakan untuk menetapkan pengujian dengan parameter pada pelatihan ini, dijabarkan sebagai berikut: 
$>>$ net=newff(minmax $(P P),[2,1],\{$ 'tansig','purelin'\},'traingd');

$>$ net.IW $\{1,1\}$;

$>$ net.b $\{1\}$;

$>$ net.LW $\{2,1\}$;

$>$ net. $b\{2\}$;

$>$ net.trainParam.epochs $=10000$;

$>$ net.trainParam. $L R=0.1$;

$>$ net.trainParam.goal $=0.01$;

$>$ net.trainParam.show $=1000$;

> net=train(net,PP,TT)

Prediksi ditentukan menggunakan persamaan sebagai berikut:

Prediksi $=\frac{(\text { output }-0,1)(b-a)}{0,8}+a$

\section{KESIMPULAN}

Kesimpulan yang dapat diambil setelah melakukan pelatihan dan pengujian data pada jaringan syaraf tiruan untuk memprediksi penjualan kelapa sawit menggunakan algoritma backpropagation adalah pemodelan terbaik pada penelitian ini adalah arsitektur 12-2-1 dengan menggunakan layer masukan 12 neuron, layer tersembunyi sebanyak 2 neuron dan layer keluaran 1 neuron. Arsitrktur 12-2-1 menghasilkan epoch sebesar 1443 iterasi, waktu 00:16, MSE pelatihan 0,00999734 dan MSE pengujian 0,04149457 dengan tingkat akurasi sebesar 92\%. Dengan arsitektur 12-2-1 tersebut selanjutnya dilakukan prediksi untuk tahun 2019 dengan total prediksi sebesar 18966 (Ton), tahun 2020 dengan total prediksi sebesar 18978 (Ton) dan tahun 2021 dengan total prediksi sebesar 18978 (Ton).

\section{DAFTAR PUSTAKA}

[1] A. Wanto and A. P. Windarto, "Analisis Prediksi Indeks Harga Konsumen Berdasarkan Kelompok Kesehatan Dengan Menggunakan Metode Backpropagation," Jurnal \& Penelitian Teknik Informatika Sinkron, vol. 2, no. 2, pp. 37-44, 2017.

[2] A. Wanto, A. P. Windarto, D. Hartama, and I. Parlina, "Use of Binary Sigmoid Function And Linear Identity In Artificial Neural Networks For Forecasting Population Density," International Journal Of Information System \& Technology, vol. 1, no. 1, pp. 43-54, 2017.

[3] A. Wanto, M. Zarlis, Sawaluddin, and D. Hartama, "Analysis of Artificial Neural Network Backpropagation Using Conjugate Gradient Fletcher Reeves in the Predicting Process," Journal of Physics: Conference Series, vol. 930, no. 1, pp. 1-7, 2017.

[4] S. P. Siregar and A. Wanto, "Analysis of Artificial Neural Network Accuracy Using Backpropagation Algorithm In Predicting Process (Forecasting)," International Journal of Information System \& Technology, vol. 1, no. 1, pp. 34-42, 2017.

[5] J. R. Saragih, M. Billy, S. Saragih, and A. Wanto, "Analisis Algoritma Backpropagation Dalam Prediksi Nilai Ekspor (Juta USD)," Jurnal Pendidikan Teknologi dan Kejuruan, vol. 15, no. 2, pp. 254-264, 2018.

[6] E. Hartato, D. Sitorus, and A. Wanto, "Analisis Jaringan Saraf Tiruan Untuk Prediksi Luas Panen Biofarmaka di Indonesia," Jurnal semanTIK, vol. 4, no. 1, pp. 49-56, 2018.

[7] S. Setti and A. Wanto, "Analysis of Backpropagation Algorithm in Predicting the Most Number of Internet Users in the World," JOIN (Jurnal Online Informatika), vol. 3, no. 2, pp. 110-115, 2018.

[8] R. E. Pranata, S. P. Sinaga, and A. Wanto, "Estimasi Wisatawan Mancanegara Yang Datang ke Sumatera Utara Menggunakan Jaringan Saraf," Jurnal semanTIK, vol. 4, no. 1, pp. 97-102,

Prediksi Penjualan Kelapa Sawit Menggunakan Algoritma Backpropagation (Delima Sinaga) | 425 
2018.

[9] A. A. Fardhani, D. Insani, N. Simanjuntak, and A. Wanto, "Prediksi Harga Eceran Beras Di Pasar Tradisional Di 33 Kota Di Indonesia Menggunakan Algoritma Backpropagation," Jurnal Infomedia, vol. 3, no. 1, pp. 25-30, 2018.

[10] J. Wahyuni, Y. W. Paranthy, and A. Wanto, "Analisis Jaringan Saraf Dalam Estimasi Tingkat Pengangguran Terbuka Penduduk Sumatera Utara,” Jurnal Infomedia, vol. 3, no. 1, pp. 1824, 2018.

[11] A. Wanto et al., "Levenberg-Marquardt Algorithm Combined with Bipolar Sigmoid Function to Measure Open Unemployment Rate in Indonesia," in Conference Paper, 2018, pp. 1-7.

[12] I. A. R. Simbolon, F. Yatussa'ada, and A. Wanto, "Penerapan Algoritma Backpropagation dalam Memprediksi Persentase Penduduk Buta Huruf di Indonesia," Jurnal Informatika Upgris, vol. 4, no. 2, pp. 163-169, 2018.

[13] S. P. Siregar, A. Wanto, and Z. M. Nasution, "Analisis Akurasi Arsitektur JST Berdasarkan Jumlah Penduduk Pada Kabupaten / Kota di Sumatera Utara," in Seminar Nasional Sains \& Teknologi Informasi (SENSASI), 2018, pp. 526-536.

[14] A. Wanto, "Optimasi Prediksi Dengan Algoritma Backpropagation Dan Conjugate Gradient Beale-Powell Restarts," Jurnal Teknologi dan Sistem Informasi, vol. 3, no. 3, pp. 370-380, Jan. 2018.

[15] B. K. Sihotang and A. Wanto, "Analisis Jaringan Syaraf Tiruan Dalam Memprediksi Jumlah Tamu Pada Hotel Non Bintang," Jurnal Teknologi Informasi Techno, vol. 17, no. 4, pp. 333346, 2018.

[16] M. A. P. Hutabarat, M. Julham, and A. Wanto, "Penerapan Algoritma Backpropagation Dalam Memprediksi Produksi Tanaman Padi Sawah Menurut Kabupaten/Kota di Sumatera Utara," Jurnal semanTIK, vol. 4, no. 1, pp. 77-86, 2018.

[17] Y. Andriani, H. Silitonga, and A. Wanto, "Analisis Jaringan Syaraf Tiruan untuk prediksi volume ekspor dan impor migas di Indonesia," Register - Jurnal Ilmiah Teknologi Sistem Informasi, vol. 4, no. 1, pp. 30-40, 2018.

[18] A. Wanto, "Penerapan Jaringan Saraf Tiruan Dalam Memprediksi Jumlah Kemiskinan Pada Kabupaten/Kota Di Provinsi Riau," Kumpulan jurnaL Ilmu Komputer (KLIK), vol. 5, no. 1, pp. 61-74, 2018.

[19] I. S. Purba and A. Wanto, "Prediksi Jumlah Nilai Impor Sumatera Utara Menurut Negara Asal Menggunakan Algoritma Backpropagation," Jurnal Teknologi Informasi Techno, vol. 17, no. 3, pp. 302-311, 2018.

[20] A. Wanto, "Prediksi Angka Partisipasi Sekolah dengan Fungsi Pelatihan Gradient Descent With Momentum \& Adaptive LR," Jurnal Ilmu Komputer dan Informatika (ALGORITMA), vol. 3, no. 1, pp. 9-20, 2019.

[21] N. Nasution, A. Zamsuri, L. Lisnawita, and A. Wanto, "Polak-Ribiere updates analysis with binary and linear function in determining coffee exports in Indonesia," IOP Conference Series: Materials Science and Engineering, vol. 420, no. 12089, pp. 1-9, 2018.

[22] A. Wanto, "Prediksi Produktivitas Jagung Indonesia Tahun 2019-2020 Sebagai Upaya Antisipasi Impor Menggunakan Jaringan Saraf Tiruan Backpropagation," SINTECH (Science and Information Technology), vol. 1, no. 1, pp. 53-62, 2019.

[23] B. Febriadi, Z. Zamzami, Y. Yunefri, and A. Wanto, "Bipolar function in backpropagation algorithm in predicting Indonesia's coal exports by major destination countries," IOP Conference Series: Materials Science and Engineering, vol. 420, no. 12089, pp. 1-9, 2018.

[24] A. Wanto et al., "Analysis of Standard Gradient Descent with GD Momentum And Adaptive LR for SPR Prediction,” 2018, pp. 1-9. 